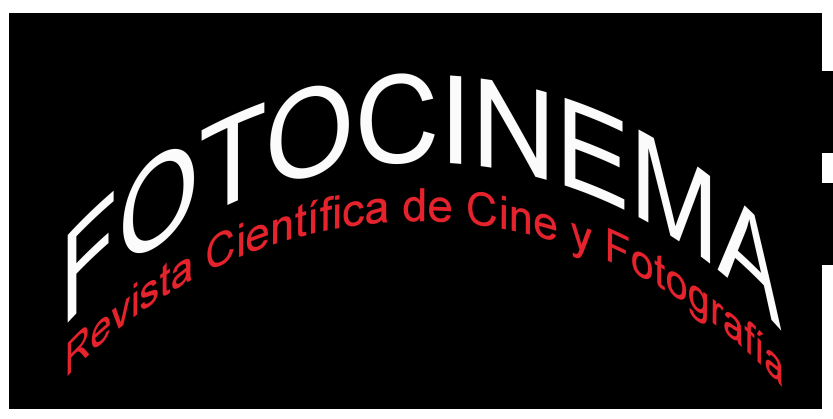

\title{
LA AUTORREFLEXIÓN EN LA COMEDIA CLÁSICA ARGENTINA
}

\section{SELF-REFLEXIVITY IN CLASSIC ARGENTINE COMEDY}

\author{
Dr. Alejandro Kelly Hopfenblatt \\ CONICET/Universidad de Buenos Aires, Facultad de Filosofía y Letras, Instituto de Artes del Espectáculo \\ "Raúl H. Castagnino", Argentina \\ alejandro.kelly.h@gmail.com
}

\section{Resumen:}

A comienzos de la década de 1940 el cine argentino se encontraba en un proceso de consolidación industrial y aburguesamiento de sus relatos. Frente a ello, los astros populares que habían dominado la producción de los años anteriores se vieron enfrentados a la necesidad de reformular sus personajes y películas para mantener el favor del público. En medio de un escenario donde los empresarios prescindían de ellos y las publicaciones los criticaban, buscaron vías para insertarse en la nueva realidad. Una estrategia recurrente fue la comedia autorreflexiva, a partir de la cual se desmontaron los contratos implícitos con el público y se pusieron en escena los mecanismos internos de la industria del espectáculo. En estos films explicitaban para el público las transformaciones del campo y sus posibilidades individuales de incorporación en el mismo. Estrellas como Niní Marshall y Libertad Lamarque apelaron a este tipo de cine para ensayar alternativas, mostrar sus limitaciones y exhibir la artificialidad de las convenciones de la industria del cine.

\begin{abstract}
:
In the early 1940s, Argentine cinema was going through a process of industrial consolidation and the development of bourgeoisie-themed stories. Popular stars, who had ruled national film in the previous decade, faced the need to reformulate their characters and movies in order to keep their audience. In a scenario where film businessmen were getting rid of them and entertainment magazines criticized them, they looked for ways to insert themselves in this new context. A recurring strategy was self-reflective comedy, through which they dissasembled their implicit contracts with their audience by showing them the inner works of the entertainment industry. In these movies, they made explicit the transformations within the field and the possibilities they presented for popular actors. Stars such as Niní Marshall and Libertad Lamarque made use of this strategies to test alternatives, show their limitations and display the artificiality of film industry's conventions.
\end{abstract}

\section{Palabras clave:}

cine clásico argentino; comedia cinematográfica; autorreflexión; industria del entretenimiento; Niní Marshall; Libertad Lamarque.

Keywords:

Argentine Classical Cinema; Film Comedy; Self-Reflexivity; Entertainment Industry; Niní Marshall; Libertad Lamarque. 
Cómo citar: Kelly Hopfenblatt, A. (2018). La autorreflexión en la comedia clásica argentina. Fotocinema. Revista científica de cine y fotografía, $\mathrm{n}^{0} 16$, pp. 265-288.

Disponible: http://www.revistas.uma.es/index.php/fotocinema/

DOI: http://dx.doi.org/10.24310/Fotocinema.2017.voi15

\section{Introducción}

A comienzos de la década de 1940, el cine argentino se encontraba en un proceso de consolidación industrial, diversificando su producción $\mathrm{y}$ ampliando sus universos de representación. Luego de una década de prevalencia de films orientados a un público popular, se comenzó a apelar a un espectro más amplio de espectadores que incluyera las clases medias y altas. Un fenómeno fundamental en esta dirección fue la renovación de directores, guionistas y estrellas, incorporando a la industria cinematográfica nuevas figuras que pudieran llevar adelante estos cambios.

Como respuesta a este reclamo se fue consolidando hacia comienzos de los años '40 un nuevo modelo de representación, la comedia burguesa, presentando imágenes y temáticas más cercanas a los imaginarios de las clases altas. Denominado habitualmente en la tradición cinematográfica argentina como 'comedia de teléfonos blancos', este cine presentaba escenarios lujosos que idealizaban el universo burgués a partir de relatos románticos y familiares protagonizados por adolescentes virginales e ingenuas. Estas comedias burguesas supusieron un éxito de taquilla y crítica, festejadas por presentar universos idílicos donde primaba la armonía social y los valores tradicionales (Kelly Hopfenblatt, 2015).

Estas transformaciones incidieron fundamentalmente en los géneros populares como la comedia de cómicos y el melodrama tanguero que habían dominado la producción fílmica de los años treinta. Con ellos se habían consagrado las primeras estrellas del cine clásico argentino como Libertad Lamarque, Luis Sandrini y Niní Marshall. A pesar de que contaban con el apoyo del público masivo, sus películas no habían sido siempre celebradas 
por la crítica o los sectores dirigentes de la sociedad, quienes les reclamaban un cambio en los imaginarios que presentaban.

El surgimiento de la comedia burguesa llevó a que estas figuras consagradas debieran enfrentar la necesidad de repensar sus textos estrellas y los relatos en que se inscribían, buscando una renovación que no rompiera sus contratos implícitos con el público. En el marco del panorama incierto que generaba una industria cinematográfica en reconfiguración emprendieron distintos ensayos de nuevos personajes e historias para probar la aceptación del público.

Sandrini, por ejemplo, comenzó a alejarse de su personaje chaplinesco opuesto al trabajo y a la movilidad social, y pasó a protagonizar relatos integradores que culminaban con su alejamiento de la pobreza, como Secuestro sensacional!!! (Luis Bayón Herrera, 1942) y La danza de la fortuna (Luis Bayón Herrera, 1944). El director Manuel Romero, por su parte, que había filmado romances interclase que negaban la posibilidad de la conciliación de clases, comenzó a presentar historias sobre empresarios y trabajadores que formaban acuerdos mutuamente beneficiosos, como Elvira Fernández, vendedora de tiendas (1942).

Dentro de estas iniciativas de reformulación de las comedias populares se destaca un conjunto de películas que apelaron al humor autorreflexivo como una estrategia orientada a explicitar y discutir los cambios en las convenciones representacionales sobre las cuales se estaba estructurando la comedia fílmica. Entre ellas se pueden destacar Nace un amor (Luis Saslavsky, 1938), Mañana me suicido (Carlos Schlieper, 1942) y El fabricante de estrellas (Manuel Romero, 1943). Estas estrategias narrativas suponían, como señala Soledad Pardo (2017), una tensión en el lenguaje clásico cinematográfico al romper con sus pretensiones de transparencia y explicitar sus mecanismos de producción.

Si bien un enfoque formalista sobre este corpus permite poner en discusión la propia idea de 'cine clásico', las propuestas que estructuran estos films invitan a tomar en cuenta otras perspectivas. En este sentido, resulta pertinente retomar los planteos de Jane Feuer (1995) con respecto a la 
autorreflexividad de los musicales de Hollywood de los años '40. Allí la autora establece la existencia de un conjunto de films que trascienden la autorreferencialidad propia del género para plantearse como obras autorreflexivas que exponen los mecanismos internos del musical. Este proceso oscila entre la desmitificación y la remitificación, es decir la evidenciación de los mecanismos de producción de las películas para luego construir un nuevo mito superador. De este modo, no sólo se plantea una mirada crítica sobre la propia dimensión musical de los films, sino que se lo representa en su relación con el público, con el campo del entretenimiento y con la historia propia de su género.

De un modo similar, las comedias autorreflexivas de las figuras populares en Argentina no buscaban la parodia o la sátira, sino que se apuntaba a presentar los problemas y las vicisitudes que estas estrellas encontraban en el desarrollo de sus tareas. Desarmando las convenciones y arbitrariedades sobre las que se construía el relato fílmico, estos films se proponían exponer las bases sobre las cuales se habían construido sus relatos populares. La autorreflexión permitía asimismo resignificar los escenarios y las estrellas en un nuevo marco, expresando así la disputa entre el humor disruptivo de la comedia popular y la intención armónica de la incipiente comedia burguesa.

Es el objetivo de este trabajo detenerse en dos casos paradigmáticos de esta tendencia, Hay que educar a Niní (Luis César Amadori, 1941) y Eclipse de sol (Luis Saslavsky, 1943). La elección de estos films radica en que sus protagonistas fueron las dos principales estrellas femeninas del cine argentino en la década de 1930. Tanto Niní Marshall como Libertad Lamarque, respectivamente, explicitaron en estas películas los inconvenientes que vivían dentro de la industria, estableciendo para ello un juego de complicidades con los espectadores. Es así que para analizarlas nos detendremos en las dificultades de ambas actrices dentro del cine argentino de comienzos de los años cuarenta, para luego profundizar en el modo en que ambos films representan estos escenarios. Consideraremos, en este sentido, la presencia de nuevos modelos femeninos, las referencias a las imposiciones 
de la industria del entretenimiento y las relaciones entre lo popular y lo burgués que se ponen en tensión a lo largo de los relatos.

\section{Algunas consideraciones sobre la comedia cinematográfica clásica en Argentina}

Las dos primeras películas sonoras argentinas que dieron inicio a la producción industrial fueron iTango! (Luis Moglia Barth, 1933) y Los tres berretines (Enrique Susini, 1933). En ambas ya se presentaba claramente la dimensión popular que caracterizaría los primeros años de la producción fílmica en Argentina, presentando escenarios ligados al arrabal y al mundo de los inmigrantes. A lo largo de la década, de la mano de figuras como Luis Sandrini, Libertad Lamarque, Niní Marshall y Pepe Arias, se consolidó un estilo de representación que exaltaba las tradiciones de los sectores populares y trabajadores y rechazaba la modernidad de las clases medias y altas.

Matthew Karush (2012) plantea que en este cine se presentaba una visión dicotómica basada en la puesta en escena de un enfrentamiento irreconciliable entre sectores de la sociedad. El surgimiento de la comedia burguesa en los años '40 puede ser pensado, por lo tanto, como una búsqueda de representaciones que se alejaran de esta visión y propusieran puntos de encuentro para esta sociedad dividida. Los primeros éxitos de este cine, como Así es la vida (Francisco Mugica, 1939) o Los martes, orquídeas (Francisco Mugica, 1941) culminaban con matrimonios interclases, ascensos sociales y el triunfo del hogar familiar.

Estas transformaciones eran acompañadas desde las publicaciones especializadas con un reclamo de que las figuras populares transformaran sus rutinas y las historias que representaban. En este sentido, en octubre de 1940, el Heraldo del Cinematografista señalaba la necesidad de cambiar los modelos gastados del cine cómico de directores como Manuel Romero, Luis César Amadori y Luis Bayón Herrera. Al mismo tiempo, destacaba como figuras convocantes de la cinematografía argentina las figuras de Paulina 
Singerman, Luis Sandrini, Pepe Arias, Libertad Lamarque o Niní Marshall, quienes eran justamente los principales protagonistas de los films de aquellos realizadores. La paradoja entre su éxito comercial y la necesidad de recambio radicaba, para la publicación, en la necesidad de seguir el ejemplo de Hollywood y salir del 'modelo Sennett'. De esta forma se refería a la transición en el cine norteamericano del slapstick hacia la comedia sofisticada, lo cual había significado una legitimación del género a partir del recambio de figuras, escenarios y temáticas (Heraldo del Cinematografista, 23 de octubre de 1940).

Estas comparaciones con el cine de Hollywood nos permiten retomar los postulados de autores como Pablo Echart (2005), quien, al estudiar la comedia romántica norteamericana de los años treinta, recupera las categorías de comedia antigua y nueva que utiliza Northop Frye para hablar del teatro griego. En este sentido, Frye emparenta la comedia antigua con una modalidad disruptiva, de crítica social y política, mientras que la nueva remite más a las costumbres y tramas románticas, con un estilo que sería luego retomado por la comedia burguesa. Esta distinción permite abordar las tradiciones de la comedia teatral y su relación con las transformaciones del género en el cine, sirviendo como marco de análisis más allá de las diferencias históricas y culturales.

El paso de la comedia popular a la burguesa, pensado desde esta óptica, puede ser entendido como un proceso de legitimación, retomando este término según lo piensa David Savran (2009) para estudiar el teatro estadounidense de los años veinte. Este concepto apunta a un valor de la producción que no reside en lo comercial sino en una percepción de distinción por parte de la crítica y el público general. Para legitimarse, las formas espectaculares masivas deben diferenciarse e incorporar elementos ligados al mundo de las esferas dirigentes de la sociedad.

Fue este el camino que debió seguir la comedia popular en el campo cinematográfico argentino. La necesidad de esta renovación era acentuada en esos años por el cuestionamiento que, desde dentro de la industria, comenzaba a aquejar a las principales figuras populares. Un lugar central en 
estas dinámicas lo ocuparon las problemáticas contractuales que surgieron entre varias de las principales figuras y los empresarios del sector.

Las estrellas al ser el motor de los mayores ingresos dentro de la industria, eran al mismo tiempo los trabajadores mejor remunerados. En momentos de crecimiento de la producción, esto había sido festejado, ya que había implicado la conformación de una cinematografía sólida. En 1939, la revista Sintonía lo expresaba de este modo:

Los grandes sueldos son, por otra parte, un detalle bien elocuente del adelanto del cinematógrafo argentino. Los astros y estrellas de primera magnitud perciben elevados emolumentos, tanto como los que definen la cotización comercial de las figuras del cine americano (Sintonía, año V, 23 de agosto de 1939, $\left.\mathrm{n}^{\circ} 331\right)$.

Un año más tarde, sin embargo, la misma publicación, en una columna titulada El derrumbe de los astros, festejaba que se estuviera cuestionando a estas mismas figuras:

De pronto, cuando de nada sirvió para el público la presencia de una cotizadísima estrella a la que sólo era menester fotografiar para conseguir éxito y entusiasmo rayano al delirio; cuando se hizo silencio sobre la actuación de un mentado capocómico, al que sólo bastaba mirar al público un instante con cara seria para hacerlo desternillarse de risa; cuando no pasó nada en ambos casos, la cinematografía argentina acababa de dar un paso hacia adelante (Sintonía, año VI, 3 de noviembre de 1940, nº 350).

Para 1941, ya se hablaba de una crisis entre los espectadores y las principales figuras. La aparición de una nueva camada de actrices adolescentes que permitían un modelo exitoso por costos significativamente menores había significado un cambio de situación para los astros consagrados que ahora debían convencer a las productoras de su cachet. Radiolandia planteaba en este sentido:

Tratándose de aligerar los subidos presupuestos (el costo 'standard' de una película está ahora en los 200.000 pesos), se llegó a la conclusión de que un determinado número de estrellas ganaban sueldos que desequilibraban toda 
posibilidad de completar repartos numerosos y equilibrados en desmedro, lógicamente, de la calidad del film. ¿Qué hacer?

Los productores, en reciente reunión de la APPA, entidad que los agrupa, acordaron lo que estiman más adecuado para sus intereses. Luego de largas deliberaciones convinieron en que había que decapitar a los grandes sueldos. iQué Libertad Lamarque ganaba 95.00o! iQué Hugo del Carril cobraba 75.00o! iQué Sandrini y Niní Marshall estaban arriba de los 40.00o! Pues en adelante cobrarían la mitad, poco más o menos (Radiolandia, año XII, 23 de agosto de $\left.1941, \mathrm{n}^{\circ} 701\right)$.

Fue así que en estos años la principal compañía productora del país, Argentina Sono Film, prescindió de tres de las más exitosas estrellas de la década anterior: Luis Sandrini, Libertad Lamarque y Pepe Arias. Frente a los elevados cachets de las grandes estrellas, la industria fílmica comenzó a tender hacia nuevas figuras, más jóvenes y significativamente más económicas. Para estos años, la producción se encontraba ya inserta en un sistema de géneros y estrellas que tendía hacia la estandarización industrial y las productoras creían estar en posición de prescindir de sus figuras más convocantes, confiando en la posibilidad de generar alternativas con un alcance similar dentro del público masivo.

Este marco de tensiones, negociaciones y reformulación de estrategias cobró tal notoriedad que se trasladó a los propios relatos fílmicos. No era esta la primera ocasión en que la comedia fílmica representaba el mundo del espectáculo. Como señala Cecilia Gil Mariño (2015), la industria del entretenimiento fue un territorio habitual para la ambientación de los relatos en los primeros años del cine argentino, asociado a las posibilidades de ascenso e integración social que permitían la fama y el estrellato. A diferencia de esta propuesta de una consagración al alcance del público, hacia comienzos de los años '40 la industria del cine argentina ya se había configurado su propia mitología, con un sistema de estrellas consolidado. Es aquí donde se comenzó a tender hacia una mayor autoconsciencia de la comedia que llevó a estas instancias de autorreflexividad. 
De un modo similar a los musicales que estudia Feuer, la comedia fílmica ha oscilado siempre entre una línea que apela a la identificación del espectador y otra que propone una visión distanciada que permite la experiencia del humor sin la necesidad de consecuencias emocionales para el espectador (King, 2002). La autorreflexión de los films abordados en este artículo tiende más hacia esta segunda vertiente, proponiendo una puesta en escena que explicitara frente al público los cambios profundos que vivía el entretenimiento en Argentina. De este modo, tanto Niní Marshall como Libertad Lamarque tomaron esta modalidad para renovar sus personajes y su lugar dentro del campo del humor.

\section{Niní Marshall frente al mundo de las ingenuas}

Niní Marshall saltó a la fama a mediados de la década de 1930 con, una serie de locuciones radiales donde presentaba una amplia galería de personajes cómicos. Al momento de pasar al cine, Marshall fue disputada por las productoras. Frente a esta situación, su solución fue firmar diferentes contratos de exclusividad, otorgándole a cada una derechos sobre una propuesta específica. Con la compañía Lumiton se dedicó a las películas de Catita, una mujer trabajadora con aspiraciones de ascenso social, mientras que en Establecimientos Filmadores Argentinos (EFA) se dedicó a filmar películas de Cándida, la empleada doméstica gallega.

El tercer contrato, con Argentina Sono Film (ASF), presentó características particulares. A diferencia de Catita y Cándida, dos caracterizaciones exitosas en sus locuciones radiales, aquí Marshall no adoptó un personaje determinado. En su lugar, interpretó generalmente a mujeres llamadas Niní que iban tomando distintos rasgos según las necesidades del guion. El ingreso de Marshall a ASF se dio en un momento en que la compañía comenzaba a tender cada vez más al gran espectáculo, por lo cual los relatos en que participaba tomaron una dimensión diferente a los de la comedia popular. 
Un rol central en ello lo ocupó el director Luis César Amadori, principal realizador de la compañía, quien, como señala Lucía Rodríguez Riva (2014), era una figura que atravesaba distintos ámbitos del espectáculo, pudiendo ser caracterizado como un 'productor cultural'. Las películas que realizó Niní Marshall bajo sus órdenes demostraban este carácter multifacético y cosmopolita, incorporando distintos escenarios, muchas veces relacionados con obras de la literatura universal o tendencias fílmicas internacionales. Podía ser así una cigarrera sevillana en Carmen (Amadori, 1943), una cortesana napoleónica en Madame Sans Gene (Amadori, 1945) o una gitana envuelta en una trama de terror en Una mujer sin cabeza (Amadori, 1947). Ricardo Manetti sostiene que con estas películas la actriz tendió

un puente entre los productos populares que no querían quebrar la línea practicada con suceso en la década de 1930 y el refinamiento de un público atento al humor de la ironía puesta sobre textos cultos más dignos de una burguesía ilustrada (2000, p. 195).

En este sentido, el debut de la actriz en ASF resulta paradigmático, ya que Hay que educar a Niní presenta a la cómica deconstruyendo el cine popular que se venía desarrollando hasta esos años para luego presentar de manera incipiente un modelo que comenzaría a primar en el campo fílmico argentino: el cine de ingenuas. Protagonizado por muchachas ingenuas, adolescentes virginales que creían en el amor puro y los valores del hogar familiar, estas películas fueron el estandarte de la irrupción de la comedia burguesa en el cine nacional. De este modo, Marshall propuso una reflexión lúdica sobre el estado de la producción cinematográfica nacional y el lugar de su figura cómica dentro de ella.

En Hay que educar a Niní la cómica encarna a Niní Reboredo, una actriz que está buscando trabajo en el mundo del cine. Cuando consigue ser contratada para encarnar a una vecina de un barrio popular, el montaje del film transforma a su personaje en una prostituta, llevándola a perder una posibilidad laboral con productores católicos. Frente a ello, la mujer decide demandar judicialmente a los productores, pero los abogados a los que recurre le ofrecen en cambio contratarla para una estafa. Es así que termina 
haciéndose pasar por la hija adolescente extramatrimonial de Tristán Montero (Francisco Álvarez), un empresario al que los abogados buscan extorsionar. Niní pasa de este modo a vivir en un internado de señoritas, mientras que crece su cariño por su falso padre, llevando a un desenlace donde se revela la verdad y se castiga a los culpables (F1).



F1. Niní Marshall junto a las ingenuas Mirtha y Silvia Legrand en Hay que educar a Niní.

El film se estructura claramente en dos secciones que responden a la dinámica propuesta por Feuer sobre la desmitificación y la remitificación del entretenimiento. Mientras que la primera mitad muestra las políticas espurias, las mentiras y las dificultades del ambiente cinematográfico, a partir del ingreso de Niní al internado se comienza a construir un nuevo verosímil de idilio y redención. Como eje central de ambas partes, Niní Marshall juega con las posibilidades que cada ambiente le brinda a su personaje cómico.

La escena inicial de Hay que educar a Niní ya explicita estas intenciones de evidenciar los artificios de la representación. El film comienza con un plano de situación, estableciendo la ubicación en los estudios ficticios de Cachimayo Films. Allí se introduce a una joven que pregunta por la señorita Rubí. Al seguirla por distintos ambientes de los estudios, Amadori va mostrando las bambalinas de la filmación, presentando pasillos y sets. En el 
set de filmación de la señorita Rubí, se presenta primeramente un plano general del ámbito de filmación, con toda la maquinaria y trabajadores involucrados, para pasar luego a la aparición de Niní.

La cómica es aquí filmada en el centro de la escena, vestida con un tapado blanco, mientras que el contorno del cuadro es cubierto por las sombras de los equipos. De este modo se resalta su centralidad y su brillo como estrella. Luego de probar el encuadre y el sonido, se revela que Niní Marshall no está encarnando a la señorita Rubí, sino que a una simple doble que ocupa su lugar para probar la puesta en escena del film que se está rodando.

De este modo se pone en primer plano el sistema de estrellas y la intención de este film de problematizarlo y deconstruirlo. Al presentar inicialmente a la propia Marshall envuelta en ropas glamorosas el film juega con estas tensiones, provocando una alteración en el contrato de la cómica con el espectador Al mismo tiempo, al plantearla luego como una simple extra, se genera un desdoblamiento entre las expectativas del espectador frente a un film de Marshall y la propia configuración de la jerarquía de estrellas interna al film ${ }^{1}$.

Esta intención de deconstruir el artificio guía las primeras secuencias del film, tomando luego un rol central como disparador del conflicto que estructura el relato. La construcción de este artificio pasa a ser el centro del conflicto de la trama cuando Niní filma una escena de una película popular ambientada en el arrabal. En su estreno, éste es presentado en un plano que remarca su carácter de film dentro del film al mostrar los propios bordes de la pantalla donde está siendo proyectado. En estas imágenes se presenta un conjunto de personajes hablando sobre una mujer de mala fama, que dentro de ese universo diegético termina siendo el personaje interpretado por Niní.

\footnotetext{
${ }^{1}$ Habiendo evidenciado este artificio, la escena siguiente se dedica a desarmar la propia ilusión de realidad creada por el cine clásico. Ello comienza con un plano que presenta a Niní hablando con una amiga sobre su reciente despido en el palco de un teatro. Cuando divisan hacia fuera del plano al novio de la protagonista, ambas mujeres comienzan a caminar a su encuentro, mientras la cámara las sigue en un travelling lateral. El palco se termina revelando eventualmente como parte del set de filmación, mostrándose nuevamente el carácter artificial del universo cinematográfico.
} 
Con esta secuencia, Amadori termina de desmontar gran parte de la ilusión de realidad propia del cine popular. Al mostrar el montaje como el principal generador de sentido, desmitifica las improntas realistas de aquel cine y enfatiza su artificialidad. Al centrar el relato en las consecuencias de esta acción, resalta su importancia dentro de las intenciones autorreflexivas del film.

Habiendo desmontado de este modo la construcción de la mitología que rodeaba al cine popular de los años '3o, Hay que educar a Niní se traslada al universo de las ingenuas que comenzaban a irrumpir en esos años dentro del cine nacional. A diferencia de los ambientes populares en que se desenvolvían los personajes de Marshall, las ingenuas no entraban en contacto con los espacios por fuera del hogar o la escuela. Es así que frente a la disrupción del humor de los cómicos en los años '30, el cine de ingenuas proponía la armonía, la conciliación y el equilibrio (Kelly Hopfenblatt, 2014) $)^{2}$.

La segunda parte de Hay que educar a Niní cumple una doble función en su tendencia autorreflexiva: construir esta nueva imagen idílica que reemplazará a la mitología popular, y reflexionar sobre el lugar de Marshall frente a este nuevo panorama. Es así que el foco principal del humor pasa a estar en la corporalidad y la gestualidad de la cómica, quien demuestra constantemente su inadecuación a este mundo.

La burla sobre la imagen de la colegiala se presenta ya desde la primera aparición de Niní vestida de niña. La cámara comienza filmándola por los pies y luego va subiendo por su cuerpo. De este modo se va descubriendo lentamente la figura de la actriz vestida como una muchacha muchos años más joven que ella. Para su personificación, Marshall juega fundamentalmente con la corporalidad y la entonación de su voz. Asume así posturas enclenques y tímidas que tienden hacia la parodia del imaginario de

\footnotetext{
${ }^{2}$ Es destacable que en esta película se produce el debut de las mellizas Mirtha y Silvia Legrand en una breve escena humorística que se construye alrededor del parecido físico entre ambas. Ambas actrices se consagrarían en la primera mitad de la década de 1940 como estrellas fundamentales del nuevo universo de ingenuas que predominaría en el cine argentino.
} 
estos personajes femeninos. Por otra parte, su voz asume un tono infantil, más cercano a los niños que a las adolescentes. En su caracterización Marshall mantiene, por lo tanto, el costado que evidencia la artificialidad de la representación. En esta línea, la interacción de Marshall con el universo de las ingenuas expresa principalmente los límites de su integración armoniosa. Esto queda evidenciado en dos escenas que presentan al conjunto de las colegialas.

La primera aparición de las niñas se da en medio de su clase de cultura física, donde, en un plano general, se las muestra ordenadas en filas en un patio de la escuela, todas vestidas de blanco, haciendo ejercicios mientras siguen el ritmo marcado por la directora. Son así una muestra del orden y la armonía que caracterizará a este universo. Sin embargo, la presencia de Niní alterará ese orden como se evidencia en la última imagen de las niñas dentro del relato. Allí, en otro plano general ambientado en los pasillos de la escuela, la protagonista guía a sus compañeras en una turba que busca rebelarse contra la vicedirectora. Ya no son aquí una grilla ordenada de figuras blancas, sino un conjunto desordenado, vestidas de gris, que corren y gritan como si fueran indios de las películas del oeste. De este modo, se expresan los límites de la comediante para ingresar en ese universo, pus su carácter sublevado atenta contra sus propias bases.

Las escenas de Niní en la escuela construyen, por lo tanto, el escenario donde se construirá una nueva mitología para la comedia, pero no sus ingredientes. Estos surgen en una trama secundaria que va ganando espacio hacia el final del relato. En ella una compañera del internado, Eugenia (Nuri Montsé), desarrolla un romance con el sobrino del señor Montero. Esta parte del relato es narrada de forma melodramática, con música incidental que resalta la sensibilidad y primeros planos de la actriz llorando o emocionándose. Luego de distintos inconvenientes, el joven le propone matrimonio y Eugenia encuentra con él y el señor Montero un nuevo hogar donde pasar a tener un esposo y una figura paternal.

La primacía de esta historia en el tramo final de la película, relegando las líneas argumentales de Niní, enfatiza las intenciones del film de ir 
construyendo un nuevo universo de representación que supla a aquél que fue deconstruido previamente. Como hemos señalado previamente (Kelly Hopfenblatt, 2014), las películas de ingenuas que proliferarían en el cine argentino de los siguientes años retomaban estas mismas líneas narrativas de jóvenes huérfanas viviendo romances virginales y buscando hogares familiares que las aceptaran y cobijaran.

El compromiso con esta nueva construcción se expresa también a partir de la disminución del carácter autorreflexivo de la trama, permitiendo la construcción de un nuevo verosímil con sus propios imaginarios. Aquí ya no operan las intenciones deconstructivas de la primera mitad del film, sino que se tiende hacia una resolución ligada a los preceptos del cine clásico, con un final feliz y una armonía recuperada.

Hay que educar a Niní expone de este modo las negociaciones que la comediante debió llevar adelante en esos años con las tendencias espectaculares de ASF, las transformaciones de la comedia hacia modelos burgueses y la propia impronta popular de su figura cómica. Al ir desarmando las bases sobre las que se construía la ilusión de sus relatos fílmicos y poner estos mecanismos en un primer plano, fue planteando un distanciamiento del cine de los años previos. Por otro lado, al interactuar con las ingenuas, fue determinando los límites que encontraba para insertarse en su mundo.

$\mathrm{Su}$ carrera posterior en ASF se conduciría, por lo tanto, en escenarios burgueses alejados de la armonía y la inocencia de estas adolescentes. Como señalamos anteriormente, en dupla con Amadori, Marshall pasó a protagonizar grandes producciones como Carmen y Madame Sans Gene, encontrando allí un espacio propio diferenciado de las nuevas estrellas femeninas. Estos films, junto con la continuidad de sus personajes de Cándida y Catita, le permitieron mantenerse en un lugar central dentro de la comedia fílmica argentina de los años '40. 


\section{Libertad Lamarque frente a las rubias platinadas}

Si Niní Marshall había sido la principal actriz cómica de la primera década del cine argentino, en el terreno del melodrama ese lugar le correspondió a Libertad Lamarque. Luego de triunfar con una serie de melodramas tangueros para los estudios SIDE, había sido contratada por Argentina Sono Film en 1938. Allí habían pulido y estilizado su imagen, convirtiéndola en una estrella glamorosa con films como Madreselva (Luis César Amadori, 1938) y Puerta cerrada (Luis Saslavsky, 1939). Entre SIDE y ASF Lamarque fue construyendo un personaje propio de la morocha argentina, ligada al arrabal, protagonista de historias de sufrimiento, engaños y abandono. Sus relatos siempre articulaban el desarrollo de las tramas con números musicales donde se consolidaba la figura de la actriz y cantante, lo cual le permitió un marcado éxito en toda Latinoamérica.

Sin embargo, a principios de los años '40 sus recaudaciones comenzaron a bajar. Frente a esta nueva realidad, la empresa decidió que la estrella ya no valía los montos de su cachet. En su autobiografía, la actriz señala que

[Mentasti] me ofreció menos dinero para celebrar un nuevo contrato (esta acción es legal) al mismo tiempo que me confesaba que había hecho un acuerdo con todos los productores argentinos para que mi cachet por película no pasara de los \$30.0oo. No contó con la posibilidad de que Don Miguel Machinandiarena, otro importante productor (...) iba a olvidarse del acuerdo... (no será ético pero también es legal) y me contrató para su sello, San Miguel, por sólo dos autos Ford menos de lo que estaba ganando (Lamarque, 1986, p. 192).

De este modo, pasó a trabajar para los Estudios San Miguel, una empresa de menor peso donde no pudo continuar su reinado de la misma manera. Frente al surgimiento de las ingenuas, Lamarque perdió tanto su lugar como modelo femenino dominante así como su acceso a honorarios elevados, donde debió reformular la imagen que la había llevado al estrellato (Paladino, 1999). Para ello incursionó en un conjunto de películas que se destacaron por un eclecticismo temático y estilístico y desajustaron su texto estrella sin permitirle formar uno totalmente nuevo. Es así que protagonizó dramas de 
época -En el viejo Buenos Aires (Antonio Momplet, 1942)-, historias ambientadas en la Francia ocupada durante la Segunda Guerra Mundial -El fin de la noche (Antonio de Zavalía, 1944)- o comedias burguesas, como Eclipse de sol.

Así como Niní Marshall pudo desarrollar una propuesta autorreflexiva a partir de su encuentro con un realizador con las características de Luis César Amadori, para el caso de Libertad Lamarque fue fundamental la figura de Luis Saslavsky. Como señala Iván Morales (2016), el realizador fue una figura polémica dentro del cine argentino al buscar la convivencia entre los géneros populares y el cosmopolitismo, formulando producciones híbridas que se alejaban de las propuestas tradicionales del medio. Eclipse de sol, adaptada de una obra de Enrique García Velloso, se entroncó en esta tendencia y, al ser la única incursión de Libertad Lamarque dentro del género de la comedia sofisticada, reforzó su carácter extraño y autorreflexivo3.

Eclipse de sol cuenta la historia de Sol Bernal (Lamarque), una cancionista de novia con Antonio (Pedro Quartucci), un joven de origen estanciero. Cuando las revistas del espectáculo anuncian su boda aparece en escena Sebastián (George Rigaud), el primo de Antonio, quien viene a prevenirlo del rechazo que la noticia genera en su familia y la posibilidad de que lo deshereden. Sol conoce a Sebastián, se enamoran inmediatamente y pronto terminan casándose sin que Antonio lo sepa. Cuando la joven se entera que Sebastián está comprometido con una novia en su estancia decide perseguirlo a su hogar familiar haciéndose pasar por una nueva empleada doméstica, Regina. Allí se producen una serie de enredos que culminan en la concreción de la pareja de Sol y Sebastián y su aceptación por parte de la familia (F2).

\footnotetext{
3 Saslavsky fue también el responsable de un intento de transformación de otro actor destacado en la comedia de los años treinta. En El loco Serenata (1939), intentó alejar a Pepe Arias de su rol tradicional de perdedor solitario y hombre sencillo. Para ello lo introdujo en un policial que remitía al realismo poético francés. Como destaca Claudio España, Saslavksy «quiso quitarle a Pepe Arias la pelusa del monologuista de sainete para elevarlo al cielo trágico del grotesco escénico y lo consigue en esa película con el dibujo arratonado del nostálgico violinista venido a menos, habitante de la orilla sin negarse al rastro de la levita que le regalaba funebreros aires de escarabajo de muelle» (España, 200o, p.168). La película fue un fracaso y Arias continuó en los años siguientes interpretando distintas variantes de su personaje ya establecido.
} 


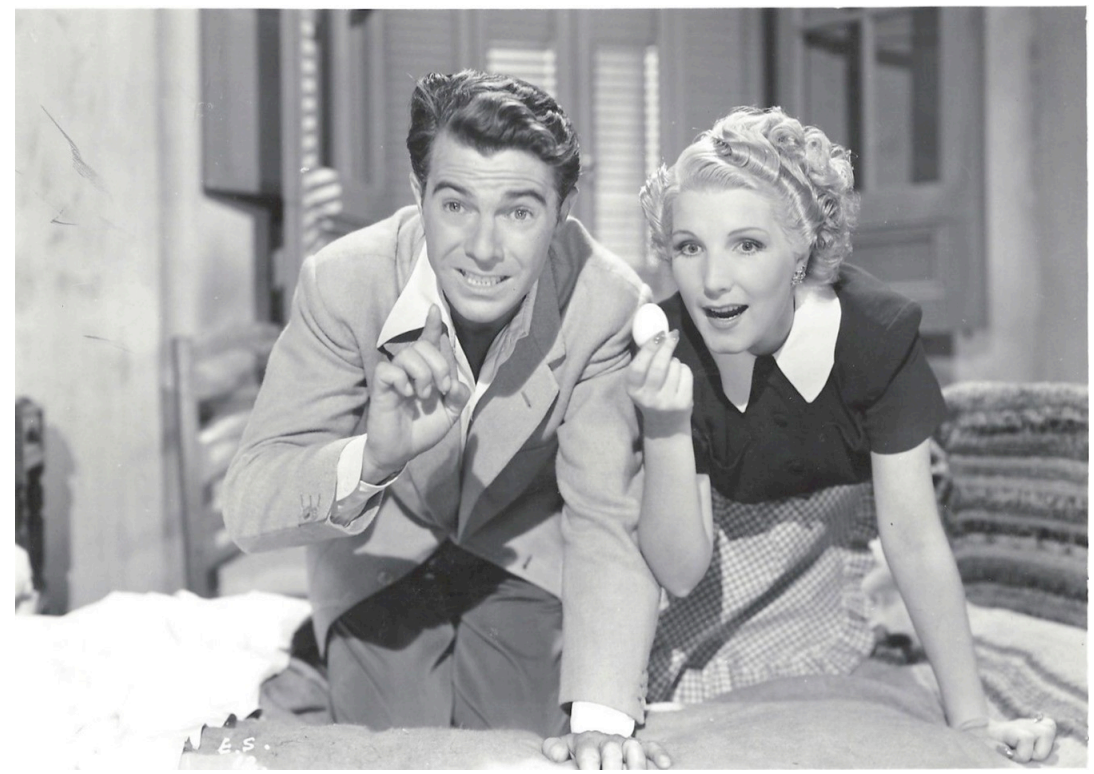

F2. Libertad Lamarque y George Rigaud en Eclipse de sol.

La primera escena del film ya plantea que es esta una historia diferente a la habitual de los films de la actriz. Aquí se la presenta con pelo rubio, sentada frente a un espejo. Su asistente le entrega una peluca oscura que se coloca mientras comienza a narrar sus aventuras de los días previos que, en forma de flashback, conformarán el relato. Allí remite al día anterior y su visita a la peluquería para aclararse el pelo, donde, en una conversación con la peluquera, comenta que su cambio de apariencia se produce «para que el público no se dé cuenta que una es la misma de siempre». Si bien su nuevo color de pelo es justificado a partir de un espectáculo que protagonizará, resulta notorio que las dos escenas musicales que protagoniza a lo largo del film sobre el escenario la presentan con una peluca oscura que cubre su cabello aclarado.

Con esta simple decisión visual y narrativa, Saslavsky ya condensa los núcleos de la autorreflexión que propone el film. Por un lado, en la mención de los deseos del público como motivo de los cambios se expone la necesidad de atender los reclamos de los espectadores. Ello es presentado desde una visión irónica ya que se propone que un simple cambio de color de pelo servirá para atender los pedidos de una nueva imagen4. Por otro lado, al

4 En esos años Radiolandia indicaba que las morochas ya no tenían lugar dentro del cine
nacional y que las rubias pasaban a ser las estrellas exclusivas (Radiolandia, año XV, 20 de 
presentar a Lamarque frente al espejo mientras explica esta situación, se refuerza el lugar de la mirada y la identidad de la actriz, estableciendo ya desde el principio esta temática como elemento central de la trama. El problema identitario adquiere aquí una doble dimensión, ya que refiere tanto al motivo recurrente del género sobre la falsa identidad como a las propias preocupaciones de Lamarque sobre su texto estrella.

En el mismo sentido, es necesario detenerse nuevamente en la paradoja de que los números musicales requieran volver a Lamarque con el pelo negro. La idea de negociación entre las exigencias del género y las convenciones de la estrella se vuelve evidente en esta decisión. El film permite la aparición de estos números musicales que remiten a la filmografía de la actriz. Lamarque cede así al nuevo género en su imagen y su registro actoral en todas las escenas salvo en aquellas que la definen de forma más esencial como lo son sus momentos como cantante. Aquí vuelve a ser la morocha porteña, cantante de revista ${ }^{5}$. Asimismo, dentro de esta negociación de la actriz con el género, Saslavsky filma estas secuencias con planos inclinados $\mathrm{y}$ fragmentados, que las vuelven extrañas y claramente artificiales.

Para terminar de desarmar el texto estrella de Lamarque, Eclipse de sol lleva a Sol al ambiente rural, planteando un diálogo con los films que la habían consagrado, como Besos brujos (José A. Ferreyra, 1937). Allí, en un modelo que Elina Tranchini (1999) ha denominado el melodrama campero, se presentaban historias de personajes urbanos que se ven inmersos en un territorio extraño, ya sea por culpa del destino o del azar, del cual debían salir victoriosos y triunfando en el amor. En el caso de Lamarque ello implicaba un mundo rural cercano a lo salvaje donde florecían los instintos más básicos de los hombres, llevando a escenarios propios del melodrama de abusos y sufrimientos.

mayo de $1944, \mathrm{n}^{\circ} 844$ ).

5 Para resaltar el tema del color de pelo, se presenta hacia principio del film un recorte de una revista especializada que habla sobre Sol Bernal y se refiere a ella como «la vedette de oscura cabellera». Junto al texto se presenta una foto publicitaria de Lamarque con su pelo morocho suelto rodeándole el rostro. 
En Eclipse de sol, en cambio, el mundo rural es presentado desde una óptica cercana a la representación de la burguesía en las comedias de esos años. El film no sale prácticamente del universo de la estancia patricia de la familia de Antonio y Sebastián. Dentro de ella, la representación espacial no remite a ranchos ni estancias campestres, sino que recupera en gran parte los lujos de los departamentos urbanos que caracterizaban a la comedia burguesa. Saslavsky pone así especial interés en ubicar en posiciones destacadas dentro del plano objetos ornamentales como lámparas, jarrones o cajas de música, que denotan ideas de alcurnia y abolengo.

$\mathrm{Al}$ ir transformando estos ambientes tan ligados al texto estrella de Lamarque, el director va operando sobre su figura, llevándola a proponer nuevas identidades. No es sólo la cabellera rubia la estrategia para ello, sino que reiteradamente a lo largo del film se presenta esta temática de modo explícito. El momento más claro sobre ello es cuando Sol se prueba los vestuarios para su nueva obra frente a un espejo. Allí pasa de usar vestidos lujosos a ponerse un uniforme de sirvienta, conduciendo a un juego de dobles identidades y malos entendidos con los tíos de Sebastián.

La apelación a lo largo del film a disfraces, pelucas, y desdoblamientos identitarios condensan, por lo tanto, el eje vertebral de la autorreflexividad de Eclipse de sol. La conformación de las figuras de las estrellas y sus universos es mostrada aquí constantemente como un juego de artificialidades donde operan distintos agentes. Libertad Lamarque se permite de este modo desarmar sus personajes populares y proponer nuevas construcciones a su público.

Sin embargo, a diferencia de Hay que educar a Niní, donde luego de deconstruir el universo de la actriz se configuraba una alternativa sólida y clara, aquí esa tarea queda difusa, acorde al estado de incertidumbre de Lamarque dentro del campo del entretenimiento nacional. Ello queda claro en el desenlace del film, donde la reconstrucción que Feuer sostiene como segunda parte del proceso autorreflexivo queda truncada.

Cuando Sol, terminando una función de su espectáculo, se entera que Sebastián ha tenido un accidente, regresa a su casa para esperarlo. En el 
apuro no se quita la peluca oscura ni las ropas con la que ha estado actuando, por lo cual esta escena final es protagonizada por una Libertad Lamarque de pelos oscuros y vestimentas andrajosas, cercana nuevamente a su personaje tradicional. La reconciliación con su pareja se da entonces en un escenario discordante en su puesta en escena, donde esta presencia física de la actriz crea una tensión con el ambiente lujoso de su departamento.

Esta tensión irresuelta contrasta con la propuesta final de Hay que educar a Niní, donde se explicitaban los límites de la actriz con este ambiente, pero al mismo tiempo se permitía la configuración de un nuevo universo de representación. Aquí en cambio, el film no trasciende a las propuestas en torno al texto actoral de Lamarque, y, luego de desarmar las bases de su personaje de 'la morocha', no termina de configurar uno nuevo para que asuma la actriz. En cambio, al proponer constantemente diferentes identidades se pone en evidencia la volatilidad que vivía la estrella en esos años y la incertidumbre de su porvenir. Efectivamente, su carrera disminuyó drásticamente en el cine argentino, y luego de tres películas más, partió al exilio, retomando su exitoso personaje tradicional en el marco de los melodramas mexicanos.

\section{Consideraciones finales}

La historiografía del cine argentino ha tenido usualmente una perspectiva evolucionista que no ha considerado la coexistencia de formas genéricas ni las transformaciones de los modelos de representación. Es así que las tensiones generadas hacia el interior de la comedia popular en los años '40 no han sido prácticamente estudiadas ni consideradas en cuanto al dinamismo y los niveles de sofisticación del género en esos años. Tanto Hay que educar a Niní como Eclipse de sol permiten vislumbrar, no sólo el nivel de conciencia que se tenía de la dimensión cismática de estas transformaciones, sino también la creatividad de las vías por las cuales la industria fílmica planteó estos cambios al público. 
Ambos film reconocen en sus relatos las transformaciones de la industria del espectáculo argentino en los años '40, proponiendo reflexiones lúdicas que tienden hacia la autorreflexión. De este modo, retomando la propuesta de Feuer (1995), podemos plantear que las estructuras de estos films presentan distintos niveles estratificados. Mientras que el más visible cumple la función de buscar el humor y entretener al público, los que subyacen apuntan a la desmitificación del entretenimiento. Al mostrar su estructura y su construcción, estas comedias van haciendo visibles las bases que conforman el mundo del espectáculo. Es así que un género que de por sí no tendía hacia una representación transparente, buscó ahondar en su contrato de autoconsciencia con el espectador para evidenciar su artificialidad y convenciones.

Las dos películas proponen en su autorreflexión exponer las implicancias del paso de la comedia antigua a la nueva, sus concesiones y los nuevos códigos que esta transformación implicaban. En los dos casos los relatos se ambientan en la industria del espectáculo, favoreciendo la autorreflexión. Ello posibilita una justificación diegética de la explicitación de sus mecanismos de producción ya que se hace referencia al terreno comercial, a los condicionamientos institucionales, y al rol del espectador.

Saslavsky y Amadori recurrieron a dos estrellas populares para presentar películas que les permitieran comentar y reflexionar lúdicamente sobre las transformaciones del cine nacional en general y la comedia fílmica en particular. Al mismo tiempo, las dos actrices encontraron en estos vehículos medios para ensayar personajes que las acercaran a las nuevas formas de la comedia fílmica argentina. Con la exposición de las convenciones narrativas y espectaculares de un cine industrial en consolidación y de sistemas de representación que se estaban estandarizando se buscaba asegurar la pervivencia de las estrellas y su contrato con el público.

Feuer señala que la autorreflexividad de los musicales de la MGM en los '40 no implicaba la radicalidad que esta estrategia supondría en los cines modernos europeos de los años '6o, donde se buscaba destruir el paradigma clásico. Más bien, sostiene, la apelación a esta modalidad en el cine clásico 
supone la construcción de relatos conservadores que buscan asegurar la continuidad de sistemas estelares y genéricos. La autorreflexión en la comedia argentina se transformó así en un punto de negociación entre las ansias disruptivas de la comedia antigua y la estabilidad de la comedia nueva, orientando el espíritu cuestionador a discursos institucionales del mercado del entretenimiento. Al confrontar modelos y figuras de la comedia popular con los de la comedia burguesa, estos films invitaban al espectador a reconfigurar sus expectativas y formular nuevos contratos con el espectáculo vernáculo.

\section{Referencias bibliográficas}

Echart, P. (2005). La comedia romántica de Hollywood de los años 30 y 40. Madrid: Cátedra.

España, C. (2000). Pepe Arias. En C. España (Comp.), Cine argentino. Industria y clasicismo. 1933-1956. Tomo I (pp.168-170). Buenos Aires: Fondo Nacional de las Artes.

Feuer, J. (1995). The self-reflexive musical and the myth of entertainment. En B.K. Grant (Ed.), Film Genre Reader II (pp.441-455). Austin: University of Texas Press.

Gil Mariño, C. (2015). El mercado del deseo. Tango, cine y cultura de masas en la Argentina de los '3o. Buenos Aires: Editorial Teseo.

Karush, M. (2012). Culture of Class. Radio and Cinema in the Making of a Divided Argentina, 1920-1946. Durham: Duke U. Press.

Kelly Hopfenblatt, A. (2014). Un modelo de representación para la burguesía: La reformulación de identidades y espacios en el cine de ingenuas. Imagofagia. Revista de la Asociación Argentina de Estudios de Cine y Audiovisual, 10. http://asaeca.org/imagofagia/index.php/imagofagia/article/view/629 $/ 539$

Kelly Hopfenblatt, A. (2015). Un cine en transición: el aburguesamiento del cine argentino visto a través de las revistas especializadas. Imagofagia. Revista de la Asociación Argentina de Estudios de Cine y Audiovisual, 12. http://www.asaeca.org/imagofagia/index.php/imagofagia/article/vie $\mathrm{w} / 827$

King, G. (2002). Film Comedy. London: Wallflower Press.

Lamarque, L. (1986). Libertad Lamarque. Buenos Aires: Juan Vergara. 
Manetti, R. (2000). Argentina Sono Film. Más estrellas que en el cielo. En C. España (Comp.), Cine argentino. Industria y clasicismo. 1933-1956. Tomo I (pp.162-221). Buenos Aires: Fondo Nacional de las Artes.

Morales, I. (2016). Luis Saslavsky: Hollywood vivido e imaginado. AURA. Revista de Historia y Teoría del Arte, 4, 31-53. http://www.ojs.arte.unicen.edu.ar/index.php/aura/article/view/328

Paladino, D. (1999). Libertad Lamarque, la reina de la lágrima. Archivos de la Filmoteca 31, 60-75. Valencia: Filmoteca de la Generalitat Valenciana.

Pardo, S. (2017). Cine clásico argentino: espacio, mirada y autorreflexividad. Los casos de La trampa y Cosas de mujer. Dixit, 26, 74-83. http://revistas.ucu.edu.uy/index.php/revistadixit/article/view/1339

Rodríguez Riva, L. (2014). Cine, revista, música: la industria cultural en las primeras películas de Luis César Amadori. En R. Manetti y L. Rodríguez Riva (Comp.), 30-50-70. Conformación, crisis $y$ renovación del cine industrial argentino y latinoamericano, (pp.4971). Buenos Aires: Editorial de la Facultad de Filosofía y Letras, Universidad de Buenos Aires.

Savran, D. (2009). Highbrown/Lowdown. Theater, Jazz and the Making of the New Middle Class. Ann Arbor: The University of Michigan Press.

Tranchini, E. (1999). El cine argentino y la construcción del imaginario criollista. En El cine argentino y su aporte a la identidad nacional (pp.101-173). Buenos Aires: Honorable Senado de la Nación. 